\title{
Social environment and height: England and Scotland 1987 and 1988
}

\author{
M C Gulliford, S Chinn, R J Rona
}

\begin{abstract}
This study was designed to investigate the social characteristics associated with the height of primary schoolchildren aged from 5 to 11. Data were analysed for 8491 representative sample children measured in England and Scotland in 1987 and 1988 and 3203 inner city children measured in England in 1987. Height was negatively associated with social class but the association was not significant after allowing for biological variables. A negative gradient of height with size of sibship was evident in white children but was less so in AfroCaribbean and Asian children. The individual associations of 11 different environmental characteristics were examined after allowing for biological factors and size of sibship. Consistent associations with height included a negative gradient of height with increasing latitude and an association of taller stature with increasing maternal age. A social class gradient in height is accounted for by associations with biological factors, particularly the parental heights; environmental attributes are weakly associated with height after allowing for biological factors.
\end{abstract}

Children's height is a sensitive indicator of their physical wellbeing, and has been recommended as a measure of their nutritional state. ${ }^{1}$ Associations between height and environmental characteristics have been investigated as possible indications of adverse influences on growth. In such investigations a number of variables including the paternal social class ${ }^{2-7}$ and employment, ${ }^{5}$ the family size, ${ }^{45}$ the number of parents at home, ${ }^{8}$ and the presence of overcrowding ${ }^{8}$ have been used to characterise social conditions during childhood. ${ }^{2}$ A gradient associating height with social class has been documented both in adults ${ }^{3}$ and children, ${ }^{4-7}$ but the existence of a gradient does not itself indicate a direct influence on growth. An association between height and a given social characteristic is difficult to interpret because of the number of confounding variables among the social characteristics of the child's environment and between social and biological factors. It is this study have shown associations between height and a number of characteristics of the social environment including paternal social class and employment, ${ }^{58}$ type of school meals, ${ }^{10}$ presence of overcrowding in the home, and the educational attainment of the mother. ${ }^{8}$ The selection of variables for inclusion in these analyses has, however, been inconsistent.

We therefore undertook the present analyses to examine the problem of confounding variables in more detail. We aimed to define the variables that should be included in analyses and to re-examine the association between children's height and paternal social class for children living in England and Scotland in 1987 and 1988.

\section{Subjects and methods}

SUBJECTS

Two samples were recruited into the National Study of Health and Growth. The initial sample included children from schools in 22 employment exchange areas in England and 14 in Scotland, which were selected by stratified random sampling. ${ }^{9}$ The characteristics of children from this sample are similar to those of the general population, ${ }^{811}$ and the sample will be referred to as 'representative' in this paper.

The inner city (selective) sample was selected by identifying 10 electoral wards in England with high incidences of overcrowding, male unemployment, or shared household amenities. In addition five wards were selected each of which had a high proportion of families from Asian backgrounds, and five each of which had a high proportion of families from AfroCaribbean backgrounds. The wards that were selected because of their ethnic composition are also inner city areas with characteristics of deprivation. For the present analysis, data measured in 1987 were analysed for the inner city sample and data measured in 1988 for the English representative sample together with that measured in 1987 and 1988 for the Scottish children. Data for the small number of nonwhite children in the representative sample were exluded from analysis as were data from children aged less than 5 or over 11 years on their last birthday.

METHODS

The methods used in the survey have been described previously. ${ }^{9}$ Children were measured at school by school nurses, $10 \%$ of measurements were checked by a full time fieldworker from the study team. Height was measured \footnotetext{
necessary to adjust for confounding variables with multiple regression analysis but this raises the question: what confounding variables should be allowed for in such analyses?

The National Study of Health and Growth is a surveillance study which was set up in 1971 to monitor the growth of primary schoolchildren in England and Scotland. ${ }^{9}$ In 1983 a second (inner city) sample was recruited. ${ }^{8}$ Reports from

Correspondence to: Dr Gulliford.

Accepted 15 August 1990

Public Health Medicine, Dental Schools London SE1 7EH

M C Gulliford

$S$ Chinn
} 
using a portable Holtain stadiometer to the last complete $0.1 \mathrm{~cm} .{ }^{12}$ The ethnic group of the child was classified according to the language spoken at home and by the fieldworker's subjective assessment of the child's ethnic group. ${ }^{8}$ The child's parent or guardian was asked to complete a self administered questionnaire containing questions relating to the child's health and the social background of the family. The questionnaire also requested information concerning the adult heights of the child's parents and the child's birth weight.

\section{ANALYSIS}

Parental heights and the child's birth weight are of greatest importance in explaining the variations in childrens' height; cases containing missing values on these continuous variables were therefore excluded from analysis. For categorical variables a 'not known' category was defined for each variable. Height standard deviation (SD) scores were used for the analysis of children's heights. The score was calculated for each child as the difference between the child's height and the mean height for English representative sample children of the same age and sex divided by the SD for that group. This method of expression standardises for age and sex and for the increasing variation in height with age. One SD score is roughly $5-7 \mathrm{~cm}$ between the ages of 5 and 11 years.

Categorical variables were classified as follows. The length of pregnancy was grouped into four categories: less than 38 weeks, 38 to 42 weeks, more than 42 weeks, or 'not known'. The number of children in the family was grouped into six categories: one, two, three, four children, five or more, or 'not known'. The age of the mother at the child's birth was categorised as: less than 20,20 to 23,24 to 27,28 to 31 , over 32, or 'not known'. The birth order of the child (the number of older siblings) was used as a proxy for maternal parity. In the inner city sample the ethnic group of the child was classified into seven categories: white, AfroCaribbean, Urdu, Gujarati, Punjabi, other Asian, 'other' and 'not known'.

Paternal social class was defined by the Registrar General's classification, which for analysis was reduced to the following categories: nonmanual, skilled manual, semiskilled and unskilled manual; a category for families headed by a single mother; not applicable and not known. Maternal social class was defined by the mother's present or previous occupation and was classified into: non-manual, skilled manual, semiskilled and unskilled manual, full time housewife, other, or not known. Paternal employment was divided into: employed, unemployed less than 12 months, unemployed more than 12 months, unemployed (duration unknown), not applicable and not known. Maternal employment was divided into: employed, not employed, at home, not applicable and not known. The hours worked by the mother outside the home were categorised as: less than 15/week, 15 to 25 , more than 25 , no outside work, or not known. Maternal educational attainment was divided into: primary, secondary, commercial or technical, university, no school education, or not known. Mother's age at finishing full time education was divided into the following categories: less than 12 years, 12 to 16 years, 17 to 19 years, 20 to 23 years, 24 or more, not applicable or not known.

The receipt of benefits included unemployment benefit, income support, and family credits; it was classified as received, not received, or not known. The receipt of free school meals was classified into received, not received, not applicable and not known. The degree of overcrowding in the home was estimated by dividing the number of people in the accommodation by the number of rooms (excluding kitchen and bathroom). This index was categorised into five groups: less than 1 person per room, 1 to $1 \cdot 24$, 1.25 to $1.49,1.50$ or more, or not known. A categorical variable was also included for country of residence (England or Scotland).

The independent associations between explanatory variables and height SD scores were estimated by multiple linear regression analysis. To take into account the potential for mutual confounding of the variables, the analysis was undertaken in three stages. Firstly, the unadjusted association between paternal social class and the children's height was examined. Secondly, a model was constructed to include all the biological variables that were independently associated with height. This model included the parental heights, the child's birthweight, the reported length of pregnancy, the birth order and the child's ethnic group (for the inner city sample). The country of residence was also included in this model for the represen-

Table 1 Height SD score by paternal social class in the representative sample and the ethnic groups of the inner city sample. Values are expressed as unadjusted mean (SE) height $S D$ score

\begin{tabular}{|c|c|c|c|c|c|c|}
\hline \multirow[t]{2}{*}{ Ethnic group } & \multirow{2}{*}{$\begin{array}{l}\text { No of } \\
\text { subjects }\end{array}$} & \multicolumn{3}{|c|}{ Paternal social class } & \multirow{2}{*}{$\begin{array}{l}\text { Single } \\
\text { mother }\end{array}$} & \multirow[t]{2}{*}{ Not known } \\
\hline & & $\begin{array}{l}\text { I-IIIA } \\
\text { Non-manual }\end{array}$ & $\begin{array}{l}\text { IIIB } \\
\text { Skilled manual }\end{array}$ & $\begin{array}{l}\text { IV-V } \\
\text { Semiskilled } \\
\text { and unskilled } \\
\text { manual }\end{array}$ & & \\
\hline $\begin{array}{l}\text { Representative sampl } \\
\text { England } \\
\text { Scotland }\end{array}$ & $\begin{array}{l}5117 \\
3374\end{array}$ & $\begin{array}{l}0.105(0.023) \\
0.062(0.030)\end{array}$ & $\begin{array}{r}0.000(0.024) \\
-0.048(0.029)\end{array}$ & $\begin{array}{l}-0.024(0.039) \\
-0.074(0.042)\end{array}$ & $\begin{array}{r}0.016(0.043) \\
-0.103(0.052)\end{array}$ & $\begin{array}{l}-0.067(0.050) \\
-0.072(0.075)\end{array}$ \\
\hline $\begin{array}{l}\text { White } \\
\text { Afro-Caribbean } \\
\text { Urdu } \\
\text { Gujarati } \\
\text { Punjabi } \\
\text { Other Asian } \\
\text { Other }\end{array}$ & $\begin{array}{r}1397 \\
388 \\
112 \\
271 \\
616 \\
120 \\
299\end{array}$ & $\begin{array}{r}0.043(0.078) \\
0.603(0.166) \\
-0.055(0.244) \\
-0.510(0.174) \\
-0.027(0.114) \\
-0.553(0.258) \\
-0.140(0.155)\end{array}$ & $\begin{array}{r}-0.236(0.051) \\
0.499(0.118) \\
-0.359(0.167) \\
-0.516(0.104) \\
-0.137(0.075) \\
-0.086(0.193) \\
0.191(0.141)\end{array}$ & $\begin{array}{r}-0.303(0.059) \\
0.187(0.171) \\
-0.123(0.208) \\
-0.749(0.131) \\
-0.067(0.069) \\
-0.387(0.213) \\
-0.138(0.169)\end{array}$ & $\begin{array}{r}-0.167(0.057) \\
0.527(0.082) \\
-0.685(0.398) \\
0.454(0.469) \\
-0.001(0.189) \\
-0.457(0.301) \\
0.553(0.178)\end{array}$ & $\begin{array}{r}-0.351(0.070) \\
0.712(0.112) \\
-0.534(0.167) \\
-0.718(0.131) \\
-0.271(0.089) \\
-0.412(0.225) \\
-0.385(0.130)\end{array}$ \\
\hline
\end{tabular}


tative sample. The sibship size was also included in this model because of its strong association with children's height. The resulting model was used to adjust individually the associations of each of the remaining social characteristics with height SD score.

Finally all these social variables were included simultaneously and their independent effects assessed using a stepwise procedure with backward elimination of the least associated variable at each step. A conservative probability of 0.10 was used to retain variables in this model. ${ }^{13}$ In each analysis the height SD scores of the children were used as the dependent variable. Independent variables were entered as continuous variables except where the categorisation of the variable had previously been indicated.

\section{Results}

Data for the representative sample and for the inner city sample were analysed separately. Data from 11267 representative sample children (mean height SD score -0.015) measured in England in 1988 or in Scotland in 1987 and 1988 were available for analysis. After excluding cases containing missing values on continuous variables 8491 cases (mean height SD score 0.009 ) were analysed. For the inner city sample measured in England in 1987, 6580 cases (mean height SD score $-0 \cdot 168$ ) were available for analysis; after excluding cases containing missing values 3203 cases (mean height SD score -0.133 ) were analysed.

Among English representative sample children there was a significant gradient in height with paternal social class $(F=4 \cdot 42$; df 4,5112 , $\mathbf{p}=0.001$ ) (table 1). Children living in Scotland were shorter than English children $(F=6 \cdot 13$, df $1,8489, p=0.013)$. The association of height and paternal social class was also significant for
Scottish children $(F=3 \cdot 21$, df $4,3369, p=$ 0.012 ). For the inner city sample there was also a gradient of height by paternal social class, although this was not independent of ethnic group (table 1). White inner city children were shorter than white representative sample children allowing for differences in social class $(F=$ 35.61 , df 1,9869, $\mathrm{p}<0.001$ ).

Adjusting for biological variables (parental heights, length of pregnancy, birth weight, and ethnic group) eliminated the association between social class and height in England and Scotland. Additional analyses showed that adjusting for parental heights alone was sufficient to account for the social class gradient in height. Adjusting for parental heights alone also accounted for the difference in height between the representative sample and inner city white children in each social class category, but differences in height between the ethnic groups remained significant after adjusting for parental heights $(F=31 \cdot 74$, df $6,11680, p<0 \cdot 001)$.

Both the birth order and size of sibship were associated with children's heights. Height increased with increasing birth order (after adjusting for size of sibship) but the effect of size of sibship was quantitatively more important. In both England and Scotland there was a negative association between size of sibship and height SD score (table 2). In the inner city sample a trend towards decreasing height with increasing size of sibship was also seen for white children, but in the Asian and Afro-Caribbean children this gradient was diminished or absent. The first order interaction between ethnic group and size of sibship was significant $(\mathrm{F}=8 \cdot 09$, df $41,3161, \mathrm{p}<0.001)$.

The individual associations of height SD scores with social attributes, adjusted for parental heights, birth weight, length of pregnancy, size of sibship, birth order, and country of residence (representative sample) or ethnic group

Table 2 Height by size of sibship. Values are expressed as unadjusted mean (SE) SD score

\begin{tabular}{llllll}
\hline $\begin{array}{l}\text { Size of } \\
\text { sibship }\end{array}$ & $\begin{array}{l}\text { English } \\
\text { representative }\end{array}$ & $\begin{array}{l}\text { Scottish } \\
\text { representative }\end{array}$ & $\begin{array}{l}\text { English } \\
\text { inner city }\end{array}$ & Afro-Caribbean & Asian \\
\hline 1 & $0.260(0.051)$ & $0.117(0.061)$ & $0.180(0.091)$ & $0.526(0.138)$ & $-0.123(0.213)$ \\
2 & $0.067(0.020)$ & $0.051(0.025)$ & $-0.121(0.048)$ & $0.619(0.114)$ & $-0.036(0.078)$ \\
3 & $-0.014(0.028)$ & $-0.087(0.033)$ & $-0.311(0.057)$ & $0.468(0.119)$ & $-0.309(0.063)$ \\
4 & $-0.082(0.046)$ & $-0.244(0.055)$ & $-0.316(0.074)$ & $0.511(0.139)$ & $-0.231(0.074)$ \\
$\geqslant 5$ & $-0.007(0.061)$ & $-0.171(0.086)$ & $-0.522(0.096)$ & $0.438(0.154)$ & $-0.374(0.058)$ \\
\hline
\end{tabular}

Table 3 Individual associations between height SD score and social variables each adjusted for parental heights, birth weight, length of pregnancy, size of sibship, birth order, and country of residence (representative sample) or ethnic group (inner city sample)

\begin{tabular}{|c|c|c|c|c|c|c|}
\hline \multirow{2}{*}{$\begin{array}{l}\text { Independent } \\
\text { variable }\end{array}$} & \multicolumn{3}{|c|}{ Representative sample } & \multicolumn{3}{|c|}{ Inner city sample } \\
\hline & $F$ & $d f$ & p Value & $F$ & $d f$ & p Value \\
\hline $\begin{array}{l}\text { Paternal social class } \\
\text { Paternal employment } \\
\text { Maternal age } \\
\text { Maternal social class } \\
\text { Maternal employment } \\
\text { Maternal hours of work } \\
\text { Maternal education } \\
\text { Overcrowding } \\
\text { Benefits } \\
\text { School meals } \\
\text { Longitude } \\
\text { Latitude }\end{array}$ & $\begin{array}{r}1 \cdot 13 \\
1 \cdot 32 \\
4 \cdot 15 \\
0 \cdot 56 \\
3 \cdot 32 \\
1 \cdot 50 \\
1 \cdot 13 \\
1.76 \\
1.22 \\
1 \cdot 38 \\
0 \cdot 31 \\
16 \cdot 16\end{array}$ & $\begin{array}{l}4 \\
4 \\
5 \\
4 \\
3 \\
4 \\
5 \\
4 \\
2 \\
3 \\
1 \\
1\end{array}$ & $\begin{array}{r}0.339 \\
0.260 \\
<0.001 \\
0.690 \\
0.019 \\
0.199 \\
0.342 \\
0.134 \\
0.295 \\
0.247 \\
0.579 \\
<0.001\end{array}$ & $\begin{aligned} 0 \cdot 66 \\
4 \cdot 62 \\
4 \cdot 92 \\
4 \cdot 56 \\
6 \cdot 17 \\
4 \cdot 81 \\
2 \cdot 06 \\
0 \cdot 92 \\
6 \cdot 89 \\
9 \cdot 40 \\
26 \cdot 78 \\
27 \cdot 70\end{aligned}$ & $\begin{array}{l}4 \\
5 \\
5 \\
4 \\
3 \\
4 \\
5 \\
4 \\
2 \\
3 \\
1 \\
1\end{array}$ & $\begin{array}{r}0.617 \\
<0.001 \\
<0.001 \\
0.002 \\
<0.001 \\
<0.001 \\
0.068 \\
0.454 \\
0.001 \\
<0.001 \\
<0.001 \\
<0.001\end{array}$ \\
\hline
\end{tabular}


(inner city sample) are shown in table 3 . For the representative sample shorter stature was associated with younger maternal age at the child's birth and with the mother not being currently employed. The latitude of residence was also associated with height.

The use of the stepwise procedure resulted in the selection of the parental heights, the child's birth weight, length of pregnancy, size of sib-

Table 4 Model defined using stepwise procedure for representative sample. Values given are coefficient $(S E)$ for continuous variables and mean difference $(S E)$ from last mentioned category for categorical variables, each adjusted for every other variable

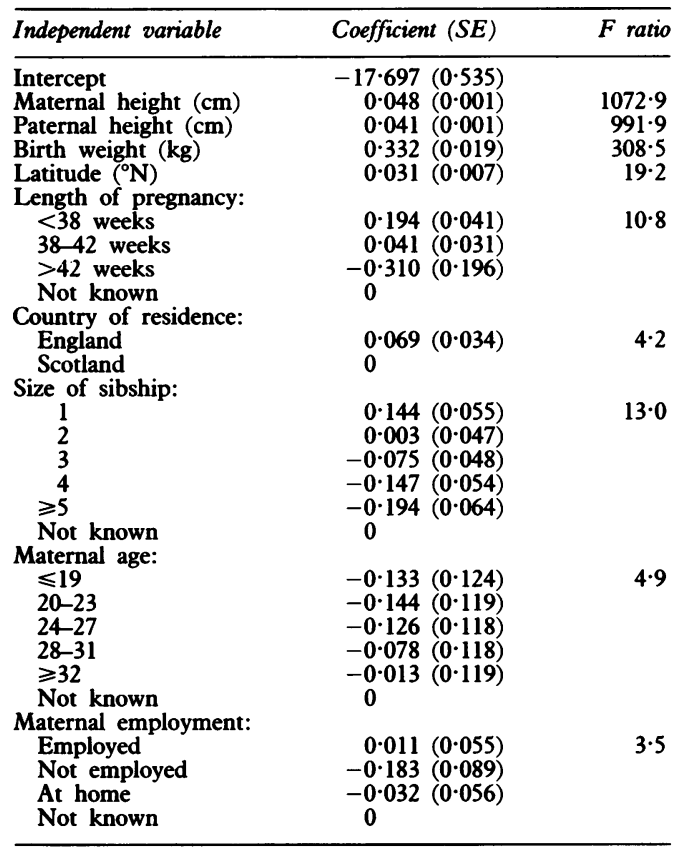

Residual mean square $0 \cdot 71$, df 8469 .

Table 5 Model defined using the stepwise procedure for the inner city sample. Values given are coefficient $(S E)$ for continuous variables and mean difference $(S E)$ from last mentioned category for categorical variables, each adjusted for every other variable

\begin{tabular}{|c|c|c|}
\hline Independent variable & Coefficient $(S E)$ & $F$ ratio \\
\hline $\begin{array}{l}\text { Intercept } \\
\text { Maternal height }(\mathrm{cm}) \\
\text { Paternal height }(\mathrm{cm}) \\
\text { Birth weight }(\mathrm{kg}) \\
\text { Latitude }\left({ }^{\circ} \mathrm{N}\right) \\
\text { Longitude }\left({ }^{\circ} \mathrm{W}\right)\end{array}$ & $\begin{array}{r}-10.117(1.006) \\
0.039(0.002) \\
0.031(0.002) \\
0.360(0.032) \\
-0.044(0.016) \\
-0.049(0.020)\end{array}$ & $\begin{array}{r}256 \cdot 9 \\
216 \cdot 4 \\
124 \cdot 7 \\
7 \cdot 6 \\
5 \cdot 7\end{array}$ \\
\hline $\begin{array}{l}\text { Length of pregnancy: } \\
<38 \text { weeks } \\
38-42 \text { weeks } \\
>42 \text { weeks } \\
\text { Not known }\end{array}$ & $\begin{array}{l}0.127(0.059) \\
-0.062(0.042) \\
-0.152(0.328) \\
0\end{array}$ & $4 \cdot 6$ \\
\hline $\begin{array}{l}\text { Ethnic group, size of } \\
\text { sibship, and interaction }\end{array}$ & 42 levels not shown & $4 \cdot 3$ \\
\hline $\begin{array}{l}\text { Birth order: } \\
1 \\
2 \\
3 \\
4 \\
5+ \\
\text { Not known }\end{array}$ & $\begin{array}{l}-0.026(0.078) \\
-0 \cdot 152(0.078) \\
-0 \cdot 100(0.084) \\
-0 \cdot 129(0.097) \\
-0 \cdot 194(0 \cdot 102) \\
0\end{array}$ & $2 \cdot 1$ \\
\hline $\begin{array}{l}\text { Maternal age: } \\
\leqslant 19 \\
20-23 \\
24-27 \\
28-31 \\
\geqslant 32 \\
\text { Not known }\end{array}$ & $\begin{array}{l}-0.031(0 \cdot 119) \\
-0.006(0 \cdot 109) \\
0.029(0 \cdot 109) \\
0 \cdot 104(0 \cdot 112) \\
0 \cdot 175(0 \cdot 113) \\
0\end{array}$ & $2 \cdot 4$ \\
\hline $\begin{array}{l}\text { School meals: } \\
\text { Not free } \\
\text { Free } \\
\text { Other } \\
\text { Not known }\end{array}$ & $\begin{array}{l}0.210(0.066) \\
0.077(0.061) \\
0.139(0.068) \\
0\end{array}$ & $4 \cdot 3$ \\
\hline
\end{tabular}

Residual mean square $0 \cdot 84$, df 3140 . ship, latitude and country of residence, maternal age, and employment position as significant associations of height (table 4). For the inner city sample, after adjusting for biological factors, ethnic group and size of sibship, taller stature was associated with: father currently employed, mother currently employed, older age of the mother, non-manual occupation of the mother, and the mother working more than 25 hours/week outside the home. Shorter stature was associated with the receipt of benefits including free school meals and with increasing latitude or longitude of the study area (table 3 ). The use of the stepwise procedure resulted in the selection of the parental heights, the child's birth weight, the length of pregnancy, the birth order, size of sibship, ethnic group (interacting with size of sibship), maternal age, type of school meals, and latitude and longitude of residence as significant associations with height (table 5).

\section{Discussion}

These data show that the heights of primary schoolchildren vary according to country of residence, ethnic group, and paternal social class. The analysis was designed to identify environmental characteristics that were independently associated with height.

In the representative sample a large proportion of the explained variation in children's heights is accounted for in association with parental heights. ${ }^{45}$ For the inner city sample the associations of birth weight and parental heights accounted for a smaller proportion of the variation in children's heights. ${ }^{8}$ This may be partly accounted for by the greater variation in the child's social and ethnic background but it has also be shown that the validity of the parents' self reported heights is less among the inner city sample. ${ }^{14}$ After allowing for parental heights, birth weight, length of pregnancy, and country or ethnic group, the gradient in height with social class was not significant; these biological factors account for much of the social class variation in children's height.

The association between the heights of parents and children is well documented and is compatible with a genetic mechanism. ${ }^{15}$ The influence of a common family environment cannot be discounted, ${ }^{16}$ but the finding of a strong parent-child association in height that accounts for the social class gradient tends to argue against an immediate environmental cause of social class differences in height during childhood. There is evidence that selection of social class by height does occur, ${ }^{17}$ but social mobility also seems to have a quantitatively small effect in determining social class gradients in height. ${ }^{18}$

There does not seem to be a strong intergenerational association for birth weight, ${ }^{19}$ but environmental factors may have important influences on growth in the antenatal period and account for some of the variation in height at older ages. ${ }^{20}$ Although there is an association between increasing birth order and increasing height, ${ }^{21}$ our findings show that this is less important than the negative association with size of sibship. Birth order was not selected as 
having an independent association with height for the representative sample, and was only weakly associated with height when selected by the stepwise procedure for the inner city sample. The pattern of association between the number of children in the family and height varied between the different ethnic groups. In each of the samples of white children (English representative, English inner city, and Scottish) height diminished with increasing family size. Among Afro-Caribbean children and Asian children the gradient of height with size of sibship was reduced or absent.

The mechanism for the effect of family size on height is not well established. It has been suggested that economic factors are responsible, ${ }^{2}$ smaller amounts of poorer quality food being available to children from larger families. ${ }^{22}$ In the National Study of Health and Growth a higher proportion of children in the ethnic minority groups come from larger families. ${ }^{8}$ The finding that the gradient of height with size of sibship is less in these groups suggests that the patterns of child care are also differently associated with family size in the ethnic groups. Simons (in a study of Sikhs living in London) found that although actual family size was not significantly greater than that of the white population, Sikhs preferred larger families including male children. ${ }^{23}$ Thus one characteristic of larger families from the ethnic minorities that might distinguish them from white families is that they are planned.

After allowing for biological factors, ethnic group, and family size the association of other social characteristics of the children were of small magnitude. More were significant in the inner city sample than in the representative sample. The age of the mother at the time of the child's birth was significantly associated with height in each of the samples and was consistently selected by the stepwise procedure. There was a gradient of increasing height with increasing age of the mother at the time of the child's birth. This association was reported previously by the National Study of Health and Growth ${ }^{5}$ and has been described in other surveys. ${ }^{44}$ The recent trend towards increasing maternal age $\mathrm{a}^{25}$ may be one of the factors associated with the secular trend towards increasing height in Britain. ${ }^{26}$ It is also relevant that there is a trend towards decreasing postneonatal mortality with increasing maternal age, and this observation is also compatible with an effect of maternal age on child care. ${ }^{27}$

Paternal unemployment is known to be associated with children's height, ${ }^{5}$ but in these analyses we found that this association was not significant in the representative sample after adjusting for parental heights, birth weight, length of pregnancy, size of sibship, birth order, and country of residence. The effect of maternal employment on children's development has been the subject of debate. ${ }^{28} 29$ Here, the employment position of the mother was associated with taller stature of primary school children. The receipt of free school meals was strongly associated with shorter stature for children in each sample but after adjustment this was significant only in the inner city sample.
In each of the samples, children's height diminished with increasing latitude of the study area, which is consistent with the gradient observed in the adult population. ${ }^{30}$ In the inner city sample height kept a negative association with latitude after adjusting for confounding variables, but for the representative sample the direction of the gradient was reversed after this adjustment. The gradient in height with latitude in this sample is thus more than accounted for by the other confounding variables.

Size of sibship is the social characteristic showing the strongest association with height, although the nature of this association depends on the ethnic background. Other social characteristics were of only marginal importance. Among the variables examined, the age of the mother at the time of the child's birth and the latitude of residence were consistently associated with height across the two samples. The receipt of free school meals and nonemployment of the mother were also associated with shorter stature. These analyses help to characterise the variables that should be included in adjustment for confounding, when attempting to characterise influences on growth during childhood; they also emphasise the greater importance of biological compared with social factors as influences on height for children living in England and Scotland.

We thank all of our colleagues in the study areas and in the department of public health medicine at St Thomas's Hospital who have contributed to the work of the National Study of who have contributed to the work of the National Study of
Health and Growth. We are indebted to Professor WW Holland Health and Growth. We are indebted to Professor WW Holland for his continued support and encouragement. The study was
funded by the Department of Health and the Scottish Home and funded by the Department of Health and the Scottish Home and
Health Department. MCG was supported by the Wellcome Health
Trust.

1 World Health Organisation. New trends and approaches in the delivery of maternal and child care in health services. Sixth report of the WHO expert committee on maternal and child care. WHO Tech Rep Ser No 600. Geneva: WHO, 1976.

2 Bielicki T. Physical growth as a measure of the economic well-being of populations: the 20th century. In: Falkner $\mathrm{F}$, Tanner JM, eds. Humans growth: a comprehensive treatise. Vol 3. 2nd Ed. New York: Plenum Press, 1986:283-305.

3 Walker M, Shaper AG, Wannamethee G. Height and social class in middle-aged British men. $f$ Epidemiol Community Health 1988;42:299-303.

4 Goldstein $\mathrm{H}$. Factors influencing the height of seven year old children-results from the National Child Development Study. Hum Biol 1971;43:92-111.

5 Rona RJ, Swan AV, Altman DG. Social factors and height of primary schoolchildren in England and Scotland. primary schoolchildren in England and Scot

6 Miller FJW, Billewicz WZ, Thomson AM. Growth from birth to adult life of 442 Newcastle-upon-Tyne children. birth to adult life of 442 Newcastle-upon-Tyne children.
British foumal of Preventive and Social Medicine 1972;26: British 224 30 .

7 Schutte JE. Growth differences between lower and middle income black male adolescents. Hum Biol 1980;52 193-204.

8 Rona RJ, Chinn S. National Study of Health and Growth: social and biological factors associated with height of children from ethnic groups living in England. Ann Hum Biol 1986;13:453-71.

9 Irwig LM. Surveillance in developed countries with particular reference to child growth. Int $\mathcal{J}$ Epidemiol 1976;5: 57-61.

10 Rona RJ, Chinn S. School meals, school milk and height of primary schoolchildren in the eighties. 7 Epidemio Community Health 1989;43:66-71.

11 Osborn AF, Butler NR, Morris AC. The social life of Britains' five year olds. A report of the Child Health and Education Study. London: Routledge and Kegan Paul, 1984.

12 Tanner JM, Whitehouse RH, Takaishi M. Standards from birth to maturity for height, weight, height velocity and weight velocity. Arch Dis Child 1966;41:454-71.

13 Armitage $P$, Berry G. Statistical methods in medical research. Oxford: Blackwell, 1987:305-7.

14 Rona RJ, Chinn S, Manning R. The validity of reported parental height in inner city areas in England. Ann Hum Biol 1989;16:41-4. 
15 Tanner JM. Use and abuse of growth standards. In: Falkner F, Tanner JM, eds. Human growth: a comprehensive treatise. 16 Carr-Hill RA. Health and income: a longitudinal study of four hundred families. Quarterly foumal of Social Affairs 1985;1:295-307.

17 Schumacher A, Knussmann R. Are the differences in stature between social classes a modification or an assortment effect? Fournal of Human Evolution 1979;8:809-12.

18 Power C, Fogelman K, Fox AJ. Health and social mobility during the early years of life. Quarterly fournal of Social Affairs 1986;2:397-413.

19 Carr-Hill R, Campbell DM, Hall MH, Meredith A. Is birthweight genetically determined. $B M \mathcal{F}$ 1987;295:687-9.

20 Brooke OG, Anderson HR, Bland JM, Peacock JL, Stewart CM. Effects on birthweight of smoking, alcohol, caffeine, socioeconomic factors and psychosocial stress. BMF 1989; 298:795-801.

21 Hermanussen $M$, Hermanussen $B$, Burmeister J. The association between birth order and adult stature. Ann Hum Ciation between birt 1988;15:161-5.

22 Cook J, Altman DG, Moore DMC, Topp SG, Holland WW. A survey of the nutritional status of schoolchildren: relation between nutrient intake and socioeconomic factors. British fournal of Preventive and Social Medicine 1973;27:91-9.
23 Simons J. Attitudes to family size among immigrant Sikhs in London. In: Coleman DA, ed. Demography of immigrant and minority groups in the United Kingdom. Proceedings of the 18th Annual Symposium of the Eugenics Society. London: Academic Press, 1982:169-92.

24 Cherry FF, Mather FJ, Mock NB. Long term effects of gynaecologic age on somatic growth in children. $7 \mathrm{Com}-$ munity Health 1987;12:108-16.

25 Werner B. Family size and age at birth: trends and projections. Population Trends 1982;33:4-13.

26 Chinn S, Rona RJ, Price CE. The secular trend of height in primary schoolchildren in England and Scotland 1972-9 primary schoolchildren in England and Scotland

27 Office of Population Censuses and Surveys. Mortality statistics, perinatal and infant: social and biological factors. DH3 series, No 21. London: HMSO, 1987:58.

28 Davie R, Butler N, Goldstein H. From birth to seven. A report of the National Child Development Study. London: Longman, 1972:42-7.

29 Graham PJ. Maternal employment. Arch Dis Child 1990;65: 565-6.

30 Rosenbaum S, Skinner RK, Knight IB, Garrow JS. A survey of heights and weights of adults in Great Britain. Ann Hum Biol 1985;12:115-27.

St Vitus, Sydenham, and the Bruegels

For over 400 years (13th to 17 th centuries) a strange form of hysterical crowd behaviour occurred in Europe. This was the dancing mania, the original St Vitus' dance. Crowds of people would suddenly begin to dance in circles and continue to the point of exhaustion. Their stomachs would swell and some would fall to the ground as if in an epileptic seizure (R H R and M P Park, fournal of the Royal Society of Medicine 1990;83:512-5).

Two saints were named as protectors of these people, St John the Baptist and St Vitus, but later St John became associated with epilepsy and St Vitus with the dancing mania. Sufferers from the dancing affliction were prone to relapse on the saints' feast days (24th and 15th June).

Vitus is first mentioned in the 5th century. He was the son of a senator in Sicily and preached in southern Italy, was credited with expelling a demon from the son of the Roman Emperor Diocletian, was tortured, and eventually suffered martyrdom.

The Epileptic Women of Molenbeek is a pen and ink drawing in the Albertina in Vienna copied by the younger Bruegel from the work of his father. It depicts sufferers not from epilepsy but the dancing mania who are about to be cured by being thrown off a low bridge into the water near to St John's chapel. The cure apparently lasted a year.

Why Thomas Sydenham applied the name of St Vitus to acute chorea is not clear. He probably lived too late to have seen the severe form of dancing mania (chorea imaginativa of Paracelsus) but may have seen a minor form of the disorder which Paracelsus called chorea naturalis and borrowed the term 'St Vitus's dance' from that.

\section{Treatment of Sydenham's chorea}

While on the subject of St Vitus's dance, a report from Kuwait (Daoud et al, Neurology 1990;40:1140-1) suggests sodium valproate as a treatment for acute chorea. Thirteen of 15 children responded completely within a week. One 7 year old who responded had had chorea for two years and had previously failed to respond to haloperidol, chlorpromazine, phenobarbitone, and diazepam. 